OPEN ACCESS

Edited by:

Yongdoo Choi,

National Cancer Center, South Korea

Reviewed by:

Yan Lil,

National Cancer Center, South Korea

Eun Seong Lee,

Catholic University of Korea,

South Korea

*Correspondence:

Yao Chen

yaofuyelu9752491@163.com

Shihong Su

shihuitunmei4216@126.com

${ }^{\dagger}$ These authors have contributed equally to this work

Specialty section:

This article was submitted to

Molecular Diagnostics and

Therapeutics,

a section of the journal

Frontiers in Molecular Biosciences

Received: 21 October 2020

Accepted: 21 December 2020

Published: 31 March 2021

Citation:

Zhang Y-F, Wu Y-F, Lan T-J, Chen Y and Su S-H (2021) Codelivery of Anticancer Drug and Photosensitizer by PEGylated Graphene Oxide and Cell Penetrating Peptide Enhanced

Tumor-Suppressing Effect on Osteosarcoma.

Front. Mol. Biosci. 7:618896. doi: 10.3389/fmolb.2020.618896

\section{Codelivery of Anticancer Drug and Photosensitizer by PEGylated Graphene Oxide and Cell Penetrating Peptide Enhanced Tumor-Suppressing Effect on Osteosarcoma}

\author{
Yi-Fei Zhang ${ }^{1 \dagger}$, Yun-Feng $\mathrm{Wu}^{2 \dagger}$, Tai-Jin Lan ${ }^{1}$, Yao Chen ${ }^{1 *}$ and Shi-Hong Su ${ }^{3 *}$
}

${ }^{1}$ Department of Human Anatomy, West China School of Basic Medicine \& Forensic Medicine, Sichuan University, Chengdu, China, ${ }^{2}$ Department of Orthopaedics, The Fourth Affiliated Hospital of AnHui Medical University, Hefei, China, ${ }^{3}$ Department of Respiratory and Critical Care Medicine, The First Affiliated Hospital of AnHui Medical University, Hefei, China

Objective: Graphene oxide (GO) has been widely used for various biological and biomedical applications due to its unique physiochemical properties. This study aimed to investigate the effects of cell penetrating peptide (CPP) modified and polyethylene-glycol- (PEG-) grafted GO (pGO) loaded with photosensitive agent 2-(1-hexyloxyethyl)-2-devinyl pyropheophorbidealpha (HPPH) and Epirubicin (EPI) (HPPH/EPI/CPP-pGO) on tumor growth in osteosarcoma.

Methods: The HPPH/EPI/CPP-pGO were prepared, and then in vitro drug release assay was conducted. The detection of singlet oxygen $\left({ }^{1} \mathrm{O}_{2}\right)$ and cellular uptake of $\mathrm{HPPH}$ was performed as well. Next, the effects of control (saline solution), CPP-pGO, EPI, HPPH, HPPH/CPP-pGO, EPI/CPP-pGO, HPPH/EPI/pGO, and HPPH/EPI/CPP-pGO were evaluated by MTT assay, colony-forming assay, and cell apoptosis assay in MG-63 cells. Furthermore, the antitumor effects of HPPH/EPI/CPP-pGO on osteosarcoma xenograft mice were unraveled.

Results: The ${ }^{1} \mathrm{O}_{2}$ generation and cellular uptake of $\mathrm{HPPH}$ were significantly increased after CPP and pGO modification compared with free HPPH. In addition, compared with control cells, CPP-pGO treatment had low cytotoxicity in MG-63 cells. Compared with free HPPH or EPI, HPPH/CPP-pGO or EPI/CPP-pGO treatment significantly inhibited cell viability and colony forming number, as well as inducing cell apoptosis. HPPH/EPI-pGO treatment showed stronger inhibition effects on MG-63 cells than HPPH/CPP-pGO or EPI/CPPpGO, and HPPH/EPI/CPP-pGO was the most effective one. Similarly, in vivo experiments revealed that, compared with control group, the tumor size and weight of osteosarcoma xenograft mice were obviously decreased after free HPPH or EPI treatment, which were further reduced in other groups, especially in HPPH/EPI/CPP-pGO group.

Conclusion: HPPH/EPI/CPP-pGO had superior tumor-inhibiting effects in vitro and in vivo on osteosarcoma.

Keywords: graphene oxide, cell penetrating peptide, epirubicin, photodynamic therapy, osteosarcoma 


\section{INTRODUCTION}

Osteosarcoma is a primary bone malignant tumor originating in mesenchymal tissue in children and adolescents, characterized by high rates of invasiveness and mortality (Ottaviani and Jaffe, 2009). Sophisticated surgical resection combined with advanced chemotherapy and photodynamic therapy (PDT) is considered as the main and effective therapeutic methods for osteosarcoma (Elkordy et al., 2018; Harrison et al., 2017). Although the diagnosis and treatments for osteosarcoma have made intensive progress, delayed or missed diagnosis still results in unsatisfactory prognosis (Elkordy et al., 2018).

Epirubicin (EPI) as a highly effective broad-spectrum anticancer drug is usually used alone or in combination with other antitumor methods to exhibit powerful therapeutic effect for solid tumors, including osteosarcoma (Plosker and Faulds, 1993; Yu et al., 2019). However, due to the poor specificity and the insensitivity of mesenchymal tissue tumors to chemotherapeutic drugs, the clinical use of EPI is compromised (Plosker and Faulds, 1993).

In recent years, as the thinnest nanomaterial, graphene oxide (GO) has attracted more attention because of exceptional physical and chemical properties, including excellent biocompatibility and good thermal stability (Joshi et al., 2015). Recent studies have reported the biomedical applications of GO, including drug delivery, biomedicine, and cancer diagnosis (Kovbasyuk and Mokhir, 2016). Previous studies have demonstrated the antitumor effects of GO by delivering targeted chemotherapy drugs (Hwang et al., 2017; Rosli et al., 2019). In addition to GO, cell penetrating peptides (CPPs) are low molecular weight peptides with remarkable capacity for membrane translocation and can carry various macromolecules into cells including peptides, proteins, and nucleic acids (Ramsey and Flynn, 2015). As an effective transport tool, CPPs have successfully introduced a variety of cytotoxic drugs into tumor cells to induce apoptosis (Cao et al., 2018; Zhang et al., 2016).

PDT is a noninvasive treatment method which has been widely applied for cancers (Fink et al., 2015; Düzgüneş et al., 2018). PDT utilizes reactive oxygen species (ROS), such as mono oxygen or free radicals produced by irradiated photosensitization with appropriate wavelengths of visible or near-infrared spectra. ROS can oxidize various organelles including mitochondria, lysosomes, and nuclear membranes, ultimately leading to irreversible tumor cell damage (Stock et al., 2018). Unfortunately, the clinical application of PDT is limited by the hydrophobicity of many irradiation photosensitizers (Ozog et al., 2016).

In the current research, polyethylene-glycol- (PEG-) grafted GO (pGO) loaded with photosensitive agent 2-(1-hexyloxyethyl)2-devinyl pyropheophorbide-alpha (HPPH) and EPI was used to enhance drug delivery to tumor cells through modification by CPP. The effects of HPPH/EPI/CPP-pGO on cell proliferation and apoptosis were investigated in MG-63 cells. Furthermore, the antitumor effects of HPPH/EPI/CPP-pGO on osteosarcoma xenograft mice were unraveled.

\section{MATERIALS AND METHODS}

\section{Preparation of GO-PEG (pGO), CPP-pGO, and HPPH/EPI/CPP-pGO}

GO nanosheets were obtained from XFNANO Materials (Nanjing, China). The morphology and ultraviolet (UV) visible spectrum of GO were measured by the atomic force microscopy (AFM) and UV visible spectroscopy. First, pGO was generated by the modification of PEG on the surface of GO. Briefly, $1 \mathrm{mg} / \mathrm{mL}$ of GO was added into distilled water containing $5 \mathrm{mM}$ of $\mathrm{N}$-hydroxysulfosuccinimide sodium and $5 \mathrm{mM}$ of $\mathrm{N}$-(3dimethylaminopropyl-N0-ethylcarbodiimide) hydrochloride and agitated at room temperature for $24 \mathrm{~h}$ to obtain the carboxyl-GO. Then, carboxyl-GO was mixed with $5 \mathrm{mM}$ of NH2-PEG by stirring at room temperature for $24 \mathrm{~h}$, and dialysis was performed to remove the excess salts and unreacted NH2-PEG. Next, to synthesize CPP-pGO, $100 \mu \mathrm{l}$ of CPP $(1 \mathrm{mM})$ and $10 \mathrm{~mL}$ of pGO $(1 \mathrm{mg} / \mathrm{mL})$ were mixed and stirred for $20 \mathrm{~h}$ at $4^{\circ} \mathrm{C}$. After centrifugation, precipitates were harvested and CPP-pGO was obtained by freeze-drying in a vacuum dryer. Subsequently, CPP-pGO nanosheets were modified with $\mathrm{HPPH}$ and EPI. In brief, $2 \mathrm{~mL}$ of CPP-pGO $(1 \mathrm{mg} / \mathrm{mL})$ was mixed with $10 \mathrm{mM}$ of $\mathrm{HPPH}$ that dissolved in dimethyl sulfoxide (DMSO) by stirring overnight, and dialysis was used to eliminate the redundant DMSO. After centrifugation for $10 \mathrm{~min}$ at $1600 \mathrm{~g}$, the unloaded $\mathrm{HPPH}$ was also eliminated. Afterwards, $0.2 \mathrm{mg}$ of EPI was added to either $1 \mathrm{~mL}$ of $\mathrm{pGO}$ $(1 \mathrm{mg} / \mathrm{mL})$ to produce EPI-loaded CPP-pGO (EPI/CPP-pGO), $1 \mathrm{~mL}$ of $\mathrm{HPPH}$-complexed pGO $(1 \mathrm{mg} / \mathrm{mL})$ to produce EPIloaded HPPH/pGO (HPPH/EPI/pGO), or $1 \mathrm{~mL}$ of $\mathrm{HPPH}$ complexed CPP-pGO nanosheets $(1 \mathrm{mg} / \mathrm{mL})$ to produce HPPH/EPI/CPP-pGO nanosheets.

\section{In Vitro Drug Release Analysis}

The drug release profiles of HPPH/EPI/CPP-pGO were evaluated by the dialysis bag method. The HPPH/EPI/CPPpGO nanoparticle solution was dispersed in dialysis bag containing $1 \mathrm{~mL}$ of PBS and $0.1 \%$ Tween 80 (pH 7.4, 6.0, or 5.0). Then, the dialysis bag was immersed in $30 \mathrm{~mL}$ of the corresponding release medium and shaken at $100 \mathrm{rpm}$ at $37^{\circ} \mathrm{C}$. Subsequently, dialysate was withdrawn at different time. Finally, the concentrations of HPPH and EPI in the dialysate were respectively analyzed by fluorescence spectrophotometer and UV/Vis spectrometry.

\section{Cell Culture and Treatment}

Human osteosarcoma cell line MG-63 was cultured in DMEM medium (Gibco). To evaluate the effects of HPPH/EPI/CPP-pGO on MG-63 cells, MG-63 cells were exposed to PBS (control), CPPpGO, EPI $(10 \mu \mathrm{g} / \mathrm{mL}), \quad \mathrm{HPPH}(1 \mu \mathrm{M}), \quad$ HPPH/CPP-pGO (containing $1 \mu \mathrm{M}$ of $\mathrm{HPPH}$ ), EPI/CPP-pGO (containing $10 \mu \mathrm{g} /$ $\mathrm{mL}$ of EPI), HPPH/EPI/pGO (containing $1 \mu \mathrm{M}$ of $\mathrm{HPPH}$ and $10 \mu \mathrm{g} / \mathrm{mL}$ of EPI), and HPPH/EPI/CPP-pGO (containing $1 \mu \mathrm{M}$ of $\mathrm{HPPH}$ and $10 \mu \mathrm{g} / \mathrm{mL}$ of EPI), respectively, for $3 \mathrm{~h}$. Next, the cells were irradiated for $5 \mathrm{~min}$ at $671 \mathrm{~nm}$ laser $\left(2-8 \mathrm{~mW} / \mathrm{cm}^{2}\right)$ and incubated for $24 \mathrm{~h}$. 


\section{Cell Viability Assay}

MG-63 cells underwent the above treatments and then were grown in 96-well plates for 24,48 , and $72 \mathrm{~h}$. Next, $100 \mu \mathrm{L}$ of CCK8 was added. After $1 \mathrm{~h}$, the absorbances at $450 \mathrm{~nm}$ were obtained using microplate spectrophotometer.

\section{Colony-Forming Assay}

400 cells/well of MG-63 cells were seeded in 6-well plates and then underwent the above treatments for 14 days. After being fixed with absolute methanol, crystal violet was used to stain cells. The cell number was calculated under light microscope.

\section{Cell Apoptosis Assay}

MG-63 cells were exposed to different treatments for $24 \mathrm{~h}$ and harvested by trypsin. After being rinsed with PBS, cells were resuspended with buffer, followed by the exposure of FITCAnnexin V and PI. Cell apoptosis was observed using flow cytometer (BD, CA, United States).

\section{Detection of Singlet Oxygen}

MG-63 cells were exposed to HPPH $(1 \mu \mathrm{M})$ and HPPH/CPPpGO (containing $1 \mu \mathrm{M}$ of HPPH) and then mixed with $1.0 \mu \mathrm{M}$ of singlet oxygen sensor green (SOSG). Cells were irradiated for $5 \mathrm{~min}$ at $671 \mathrm{~nm}$ laser $\left(75 \mathrm{~mW} / \mathrm{cm}^{2}\right)$ and the singlet oxygen $\left({ }^{1} \mathrm{O}_{2}\right)$ level was detected by observing SOSG fluorescence at $494 \mathrm{~nm}$ under confocal fluorescence microscope.

\section{Cell Uptake Assay}

Briefly, MG-63 cells were exposed to HPPH $(1 \mu \mathrm{M}), \mathrm{HPPH} / \mathrm{pGO}$ (containing $1 \mu \mathrm{M}$ of $\mathrm{HPPH}$ ), and HPPH/CPP-pGO (containing $1 \mu \mathrm{M}$ of $\mathrm{HPPH}$ ), respectively, for $24 \mathrm{~h}$. After being washed with PBS, cells were fixed with $4 \%$ paraformaldehyde solution and permeabilized with Triton X-100. DAPI was used for the staining of nucleus. The excitation and emission at 425 and 725 wavelengths were used for $\mathrm{HPPH}$ imaging using confocal fluorescence microscope.

\section{Animal Model and Treatments}

This study was approved by the Ethics Committee of our hospital. Healthy nude mice (18-22 g) were purchased and used for the experiments. To obtain the mouse xenograft model, $1 \times 10^{6}$ of MG-63 cells per mouse were subcutaneously inoculated. Then, xenograft mice were treated with saline solution (control group, $n=4$ ), HPPH/CPP-pGO (containing $1 \mathrm{mg} / \mathrm{kg}$ of $\mathrm{HPPH}, n=4$ ), EPI/CPP-pGO (containing $5 \mathrm{mg} / \mathrm{kg}$ of EPI, $n=4$ ), HPPH/EPI/ pGO (containing $1 \mathrm{mg} / \mathrm{kg}$ of HPPH and $5 \mathrm{mg} / \mathrm{kg}$ of EPI, $n=4$ ), or HPPH/EPI/CPP-pGO (containing $1 \mathrm{mg} / \mathrm{kg}$ of $\mathrm{HPPH}$ and $5 \mathrm{mg} / \mathrm{kg}$ of EPI, $n=4$ ) via rapid tail vein injection every other day. Twenty-four hours after every administration, mice received laser irradiation for $0.5 \mathrm{~h}$ at $671 \mathrm{~nm}$ laser $\left(2-8 \mathrm{~mW} / \mathrm{cm}^{2}\right)$. After 3 weeks, mice were treated with Adriamycin. The tumor volume and body weight of mice were observed. On day 30, the tumor from mice was obtained to calculate tumor weight.

\section{Drug Biodistribution}

For biodistribution analysis, the mice were killed after 3 weeks of treatment and the tumors and organs (spleen, kidneys, liver, lung, and heart) were collected and immediately frozen for cryosectioning at a $7 \mu \mathrm{m}$ thickness. After staining the cell nuclei in the sections with DAPI, fluorescence images of tumors and tissues were obtained using a confocal scanning laser microscope. The relative fluorescent intensity was quantified and normalized to the control group.

\section{Serum Biochemical Analysis}

After 3 weeks of treatment, serum samples were collected to analyze the levels of albumin (Alb), alkaline phosphatase (ALP), aminotransferase (AST), alanine aspartate aminotransferase (AST), total bilirubin (T-Bili), blood urea nitrogen (BUN), and the creatinine (Crea).

\section{Immunohistochemistry}

Tumor tissues were treated with formalin-fixation, paraffin embedding, and slice preparation. After deparaffinization and dehydration, the sections were treated with citrate buffer $(\mathrm{pH}$ 6.0 ), followed by the heat pretreatment at $80^{\circ} \mathrm{C}$ and blocking with endogenous peroxide. Next, the sections were incubated with Ki-67 antibody, followed by the incubation of secondary antibody. Ultimately, the sections were mounted with neutral resin and observed under a light microscope (Nikon, ECLIPSE $\mathrm{CI})$. The collected images were analyzed using Image-Pro Plus 6.0 software (Media Cybernetics, Inc., Rockville, MD, United States).

\section{Statistical Analysis}

Data were expressed as the mean \pm SD. Data comparison was performed using one-way ANOVA followed by multiple comparison using SPSS software. $P<0.05$ was considered statistically significance.

\section{RESULTS}

\section{Drug Characterization and In Vitro Drug Release of HPPH/EPI/CPP-pGO}

As determined by AFM, GO showed 100-400 nm of diameter and $4-5 \mathrm{~nm}$ of thickness (Figure 1A). An absorption peak at 230 $\mathrm{nm}$ was determined for GO (Figure 1B). Next, the amounts of $\mathrm{HPPH}$ and EPI released from HPPH/EPI/CPP-pGO were examined. The results revealed that $\mathrm{HPPH}$ was quickly released from HPPH/EPI/CPP-pGO within $5 \mathrm{~h}$ at $\mathrm{pH} 7.4$ to pH 5.0 (Figure 1C), and about $90 \%$ of $\mathrm{HPPH}$ was released within $24 \mathrm{~h}$ at $\mathrm{pH} 5.0$ (Figure 1C). In addition, HPPH/EPI/ CPP-pGO exhibited a gradually increased release of EPI from $0 \mathrm{~h}$ to $50 \mathrm{~h}$ (Figure 1D), and almost $70 \%$ of EPI was released from $\mathrm{HPPH} / \mathrm{EPI} / \mathrm{CPP}$-pGO within $50 \mathrm{~h}$ at $\mathrm{pH} 5.0$ (Figure 1D).

\section{${ }^{1} \mathrm{O}_{2}$ generation and Cellular Uptake of HPPH}

The fluorescence intensity of SOSG revealed that the ${ }^{1} \mathrm{O}_{2}$ generation of free HPPH was lower than that of HPPH/CPPpGO (Figure 2A). Confocal imaging results showed that $\mathrm{HPPH}$ pGO or HPPH/CPP-pGO treatment enhanced fluorescence intensity compared with free HPPH. Cells treated with HPPH/ CPP-pGO exhibited the strongest fluorescence intensity (Figures 2B,C). 

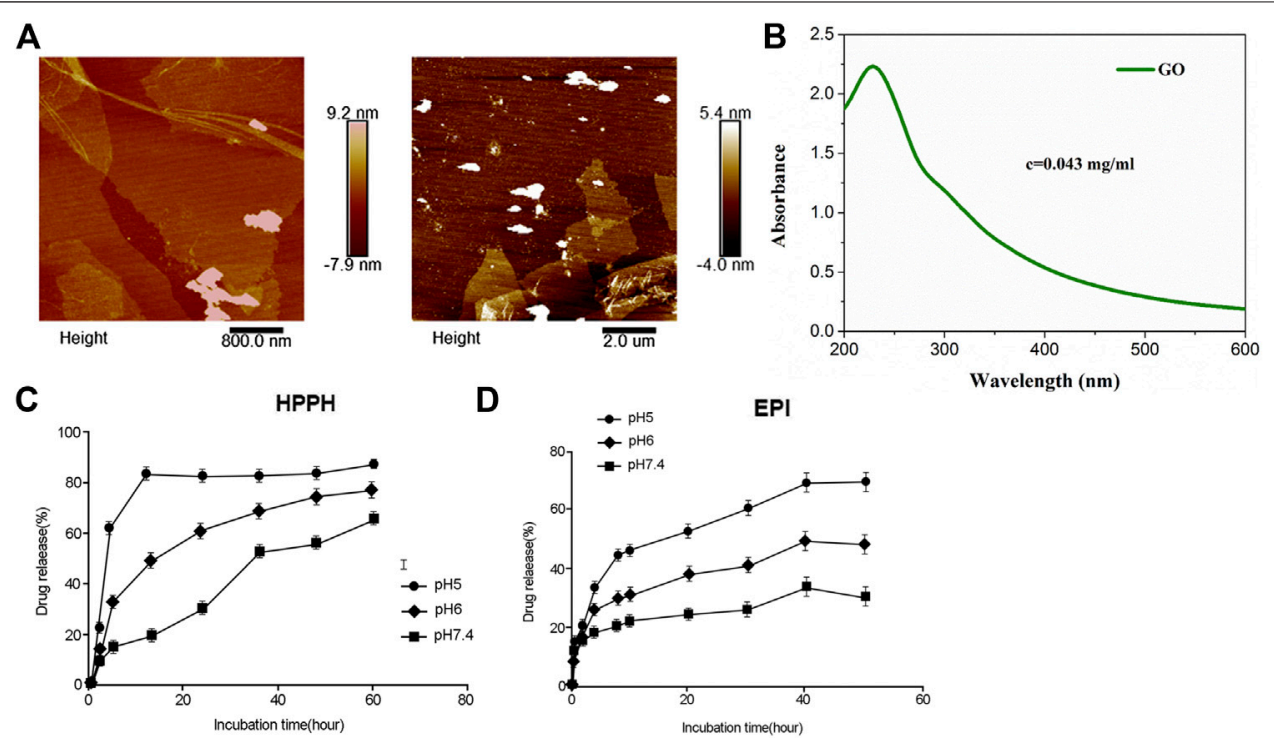

FIGURE 1 | Characterization and in vitro drug release of HPPH/EPI/CPP-pGO. (A) The representative images of GO using atomic force microscopy. (B) The ultraviolet visible absorption spectra of GO. (C) Cumulative HPPH release profiling of HPPH/EPI/CPP-pGO in phosphate-buffer saline (PBS, pH 7.4, 6.0, and 5.0). (D) Cumulative EPI release profiling of HPPH/EPI/CPP-pGO in phosphate-buffer saline (PBS, $\mathrm{pH} 7.4,6.0$, and 5.0).

\section{Antiproliferation Effect of HPPH/EPI/ CPP-pGO on MG-63 Cells}

CCK-8 assay found that, compared with control cells, CPP-pGO treatment had little effects on cell viability in MG-63 cells, indicating hypotoxicity of CPP-pGO on MG-63 cells (Figure 3A). In contrast, cell viability was obviously reduced after free EPI or HPPH treatment (Figure 3A) at 24 and $48 \mathrm{~h}$. Compared with free EPI or HPPH treatment, MG-63 cells exhibited gradually decreasing cell viability after treatment with HPPH/EPI/CPP-pGO, followed by HPPH/EPI-pGO, $\mathrm{HPPH} / \mathrm{CPP}-\mathrm{pGO}$, and EPI/CPP-pGO (Figure $\mathbf{3 A}$ ). Consistently, colony formation results exhibited similar clone number in MG-63 cells treated with PBS and CPP-pGO, while the number of colonies was decreased after free EPI or $\mathrm{HPPH}$ treatment (Figure 3B). Compared with cells treated with free EPI or HPPH, the number of colony was reduced in cells with HPPH/EPI/CPP-pGO, followed by HPPH/EPI-pGO, HPPH/ CPP-pGO, and EPI/CPP-pGO (Figure 3B). Moreover, flow cytometry analysis found that, compared with control cells, free EPI or HPPH treatment promoted the rate of apoptosis in MG-63 cells, while the percent of apoptotic cells was gradually reduced after MG-63 cells treatment with HPPH/EPI/CPPpGO, followed by HPPH/EPI-pGO, HPPH/CPP-pGO, and EPI/CPP-pGO (Figure 3C).

\section{Effect of HPPH/EPI/CPP-pGO on Osteosarcoma Xenograft Mice}

In our in vivo mouse model, the body weight of osteosarcoma xenograft mice was similar in control and treatment groups (Figure 4A). Moreover, we measured the blood biomarkers, including those of the liver and kidney toxicities, and found that they were not significantly changed by the treatment with the CPP-pGO, HPPH/EPI/CPP-pGO, or the PBS control (Supplementary Figure S1). These data suggested low toxicity due to potential nonspecific binding of CPP or pGO to normal tissues. Compared with control group, the tumor volume was reduced after HPPH/CPP-pGO or EPI/CPP-pGO treatment in a time-dependent manner, and mice in the HPPH/ EPI/CPP-pGO group showed lower tumor volume than that in the HPPH/EPI-pGO group (Figures 4B,C). Furthermore, the tumor weight of mice was the lowest in the HPPH/EPI/CPPpGO group, followed by HPPH/EPI-pGO, EPI/CPP-pGO, and HPPH/CPP-pGO groups (Figure 4D). Consistently, IHC showed that $\mathrm{Ki} 67$ expression trend in various groups was consistent with the tumor weight of mice (Figure 4E). The tumor tissues and major organs were collected $24 \mathrm{~h}$ after drug injection to study the biodistribution of the HPPH/CPP-pGO and free $\mathrm{HPPH}$ in the mouse (Figure 4F). We found strong $\mathrm{HPPH}$ fluorescence in the tumor sections of the HPPH/CPPpGO- and HPPH/EPI/CPP-pGO-treated groups, but there were no obvious fluorescence signals in the control and the free $\mathrm{HPPH}$ treated group. These results suggested the enhanced antitumor effect of HPPH/EPI/CPP-pGO on osteosarcoma xenograft mice.

\section{DISCUSSION}

This study successfully prepared HPPH/EPI/CPP-pGO. The ${ }^{1} \mathrm{O}_{2}$ generation and cellular uptake of $\mathrm{HPPH}$ were significantly increased after CPP and pGO modification compared with 


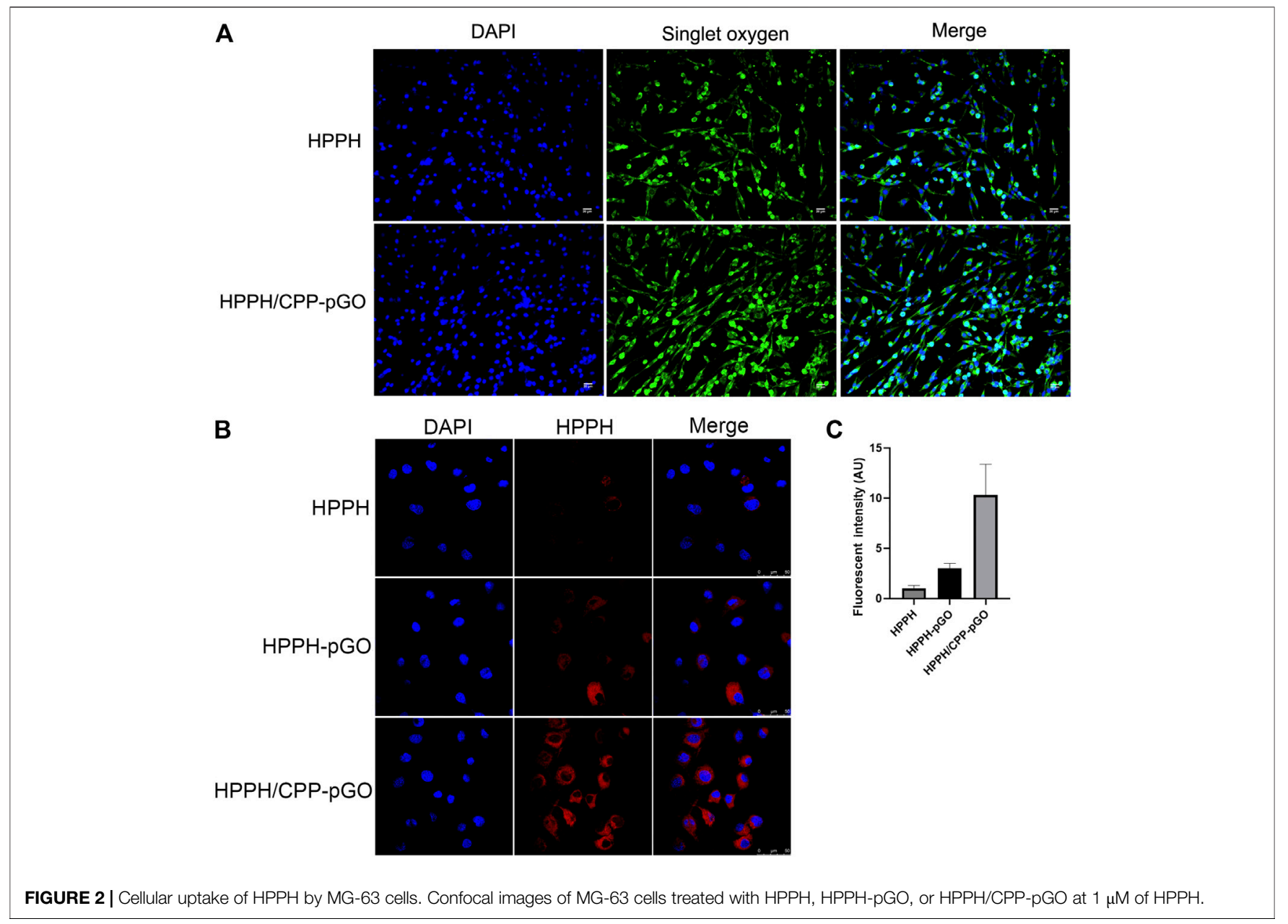

free HPPH. In addition, compared with control cells, CPPpGO treatment has less effects on cell proliferation and apoptosis in MG-63 cells. However, compared with free HPPH or EPI, HPPH/EPI/CPP-pGO treatment significantly inhibited cell viability and clone number, as well as induced cell apoptosis, followed by HPPH/CPP-pGO or EPI/CPPpGO, HPPH/EPI/CPP-pGO, and HPPH/EPI-pGO in MG63 cells. Furthermore, the tumor volume and weight of osteosarcoma xenograft mice were obviously decreased after free HPPH or EPI treatment compared with control group, which were further reduced in other groups, especially in HPPH/EPI/CPP-pGO.

EPI has been widely reported to be applied into the treatment of breast cancer (Izgi et al., 2016), gastric cancer (Pan et al., 2018), and colorectal cancer (Cacan and Ozmen, 2020). PDT using irradiated HPPH had also been reported to be an effective therapeutic method for cancers (Chen et al., 2019; Shafirstein et al., 2016; Tracy et al., 2018). Consistently, this study showed that free EPI or free HPPH reduced cell viability, colony forming number, and induced cell apoptosis in MG-63 cells. However, the clinical application of various hydrophobic photosensitizers and anticancer drugs is limited due to poor water solubility. In view of the excellent biocompatibility and highly hydrophilic nature, GO has been considered as a promising drug delivery system to overcome hydrophobicity (Deb and Vimala, 2017; Lv et al., 2016). Previous study has reported that the release of gallic acid can be improved by gallic-acid-loaded GO and gallic-acid-loaded GO targeted to suppress cancer cell growth but not normal cells (Dorniani et al., 2016). A study on drug-resistant breast cancer also showed that compared with free adriamycin, adriamycin loaded GO exhibits enhanced ability to inhibit cell proliferation and induce apoptosis (Zhi et al., 2013). Herein, in order to improve drug delivery, EPI and/or HPPI were loaded into the pGO. Consistently, we found that, compared with free EPI or HPPI, both HPPH/CPP-pGO and EPI/CPPpGO significantly diminished cell proliferation and induced cell apoptosis in MG-63 cells. Furthermore, this study revealed that the combination of EPI and irradiated HPPH exhibited preferable antitumor effect in MG-63 cells and osteosarcoma xenograft mice, which was consistent with previous clinical studies (Maria et al., 2018; Wentrup et al., 2016).

Furthermore, we focused on whether CPP modified pGO could further improve antitumor effects of EPI and irradiated 


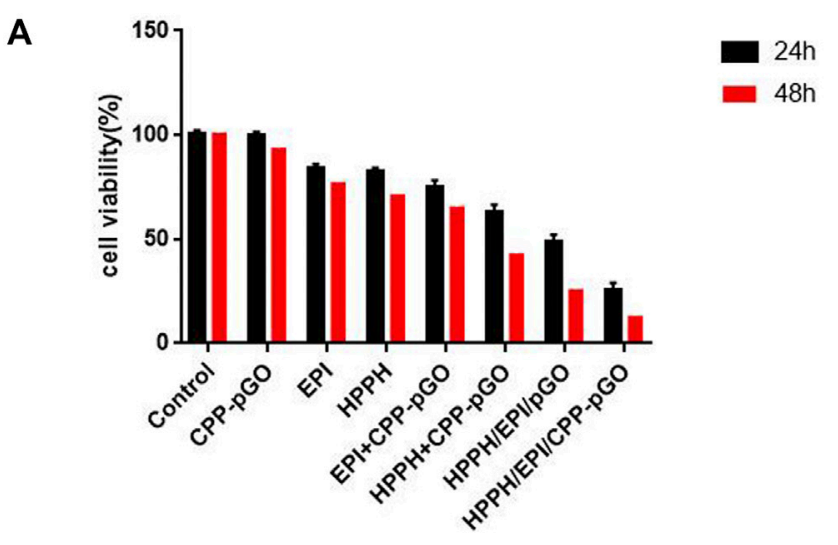

B
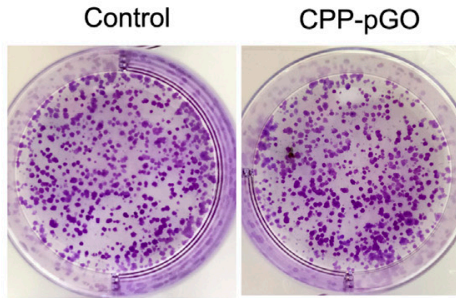

EPI

HPPH
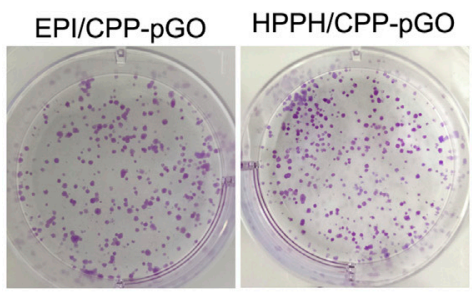

\section{HPPH/EPI-pGO HPPH/EPI/CPP-pGO}

C
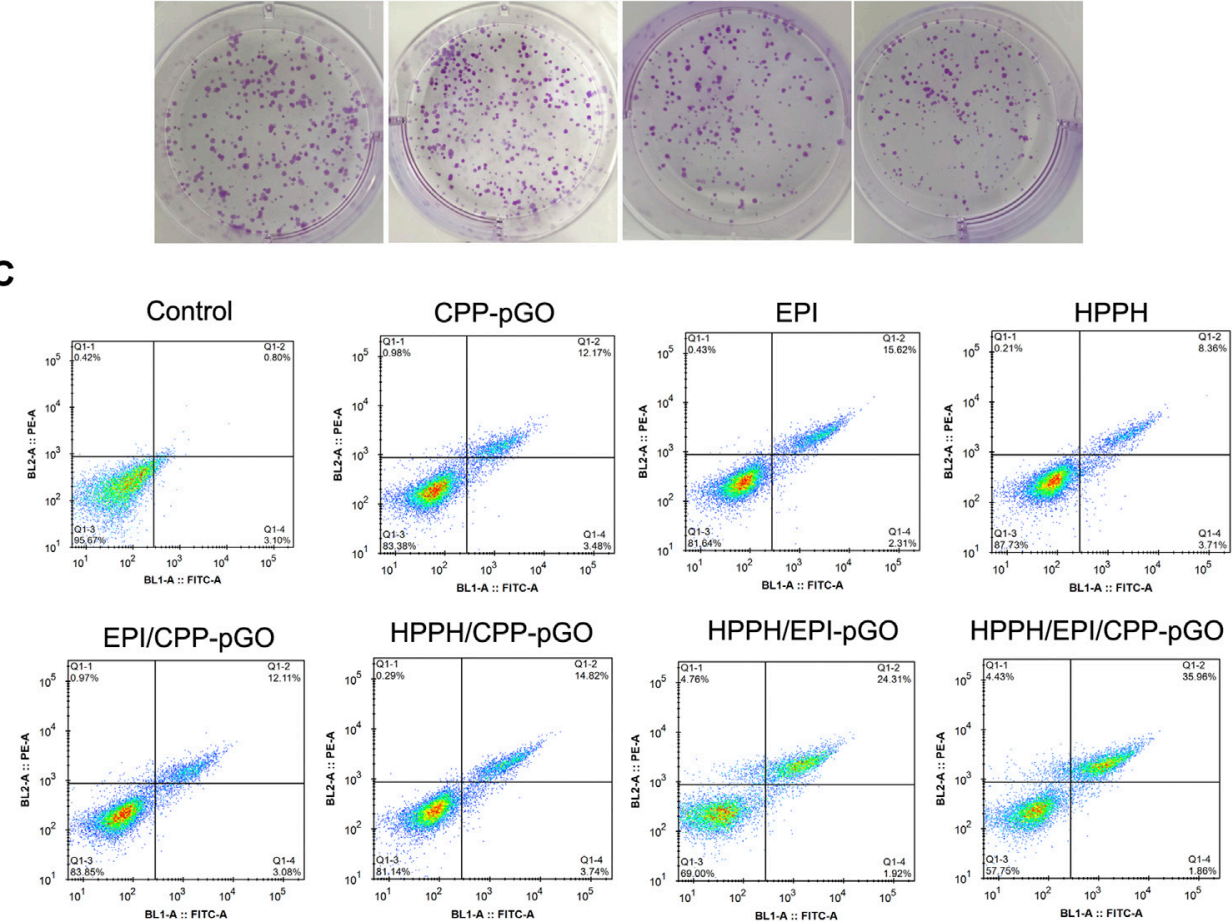

FIGURE 3 | HPPH/EPI/CPP-pGO inhibited proliferation and colony formation of MG-63 cancer cells. (A) Cell viability of MG-63 cells treated with PBS (control), CPP-pGO, EPI (10 $\mu \mathrm{g} / \mathrm{mL}), \mathrm{HPPH}(1 \mu \mathrm{M}), \mathrm{HPPH} / \mathrm{CPP}-\mathrm{pGO}$ (containing $1 \mu \mathrm{M}$ of HPPH), EPI/CPP-pGO (containing $10 \mu \mathrm{g} / \mathrm{mL}$ of EPI), HPPH/EPI/pGO (containing $1 \mu \mathrm{M}$ of $\mathrm{HPPH}$ and $10 \mu \mathrm{g} / \mathrm{mL}$ of EPI), and HPPH/EPI/CPP-pGO (containing $1 \mu \mathrm{M}$ of HPPH and $10 \mu \mathrm{g} / \mathrm{ml}$ of EPI), respectively, for 24 and $48 \mathrm{~h}$ by CCK-8 assay. (B) Colony forming number of MG-63 cells treated with PBS (control), CPP-pGO, EPI, HPPH, HPPH/CPP-pGO, EPI/CPP-pGO, HPPH/EPI/pGO, and HPPH/EPI/CPP-pGO, respectively, for $24 \mathrm{~h}$ by colony formation assay. (C) Cell apoptosis rate of U87 MG cells treated with PBS (control), CPP-pGO, EPI, HPPH, HPPH/CPP-pGO, EPI/CPPpGO, HPPH/EPI/pGO, and HPPH/EPI/CPP-pGO, respectively, for $24 \mathrm{~h}$ by flow cytometry analysis. 

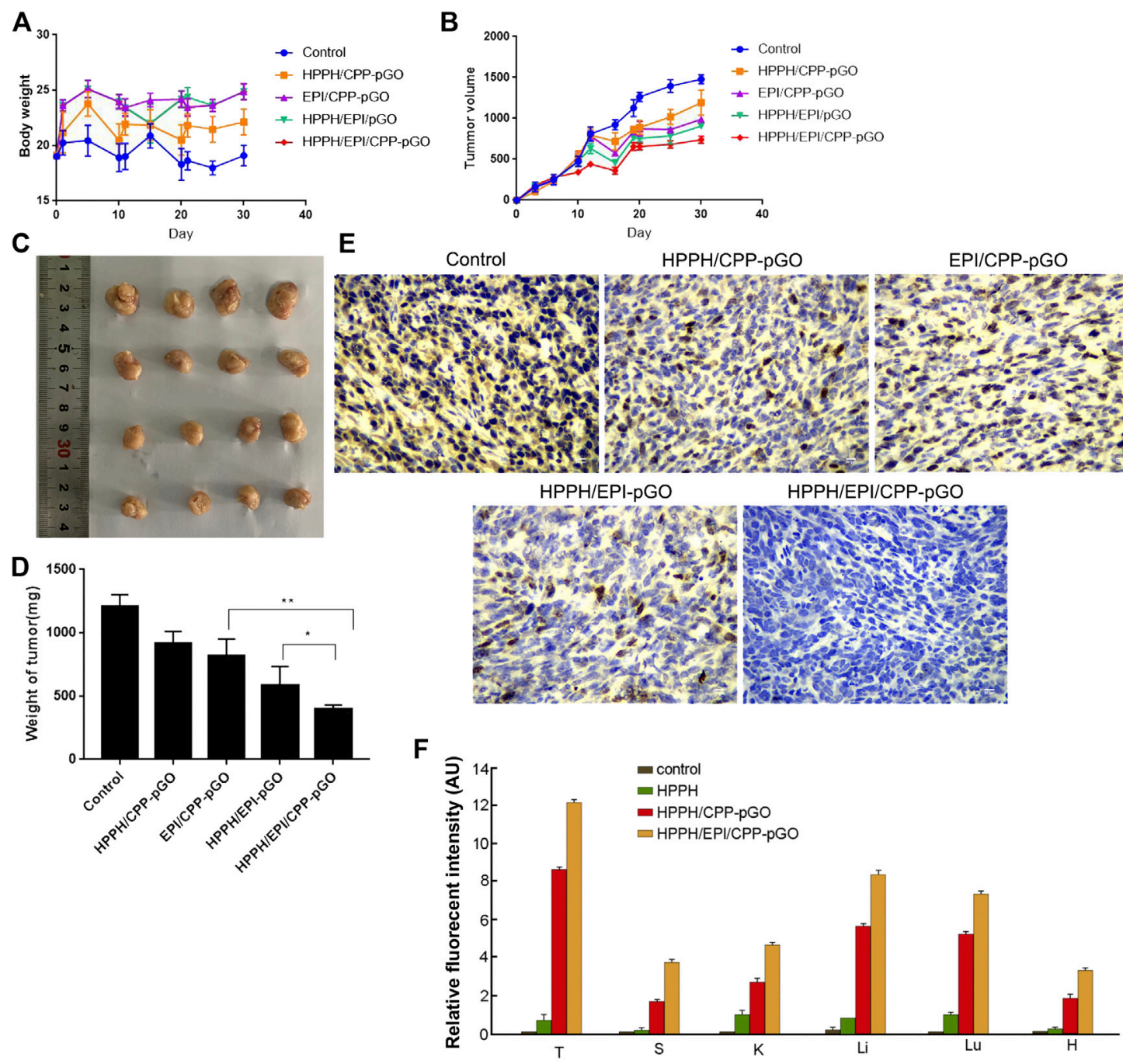

FIGURE 4 | HPPH/EPI/CPP-pGO exhibited enhanced antitumor effect in osteosarcoma xenograft mice. (A) The body weight of osteosarcoma xenograft mice with different treatments, including saline solution (control group), HPPH/CPP-pGO (containing 1 mg/kg of HPPH), EPI/CPP-pGO (containing 5 mg/kg of EPI), HPPH/EPI/pGO (containing $1 \mathrm{mg} / \mathrm{kg}$ of HPPH and $5 \mathrm{mg} / \mathrm{kg}$ of EPI), or HPPH/EPI/CPP-pGO (containing $1 \mathrm{mg} / \mathrm{kg}$ of HPPH and $5 \mathrm{mg} / \mathrm{kg}$ of EPI). (B) The tumor volumes of mice with different treatments for 30 days. (C) The tumor image of mice with different treatments on day 30. (D) The tumor weights of mice with different treatments on day 30 . (E) The Ki-67 expression of mice with different treatments by immunohistochemistry. (F) Quantitative analysis of the fluorescence intensity of the tumors and organs of mice after $24 \mathrm{~h}$ of drug injection. $\mathrm{T}$, tumor; S, spleen; K, kidney; Li, liver; Lu, lung; $H$, heart. $N=4$ in each group.

HPPH. CPPs-dependent drug delivery system has been used for the treatment of neurological diseases, asthma, ischemia, diabetes, and cancers. Dubikovskaya et al. connected octaarginine $\mathrm{R} 8$ with the anticancer drug paclitaxel through a disulfide bond to form the R8-paclitaxel covalent, and the results showed that the covalent of R8-paclitaxel was more likely to induce tumor cell apoptosis than paclitaxel alone in paclitaxel resistant tumor models (Dubikovskaya et al., 2008). In addition, in order to increase the cytotoxicity and targeted delivery of anticancer drugs, Lee et al. used chemical methods to combine doxorubicin, TAT and polymeric chitosan backbone to produce cell-penetrating chitosan/ doxorubicin/TAT chimera. Compared with chimeric doxorubicin or chitosan/doxorubicin, this chimera showed more effective cell internalization and enhanced tumor localization, thereby significantly inhibiting tumor growth (Lee et al., 2011). Consistently, our study confirmed that $\mathrm{HPPH} / \mathrm{EPI} / \mathrm{CPP}$-pGO treatment further inhibited cell growth in vitro and in vivo compared with HPPH/EPI-pGO. These results indicated that HPPH/EPI/CPP-pGO possessed enhanced antitumor effects.

In conclusion, this study successfully developed HPPH/EPI/ CPP-pGO, which had superior osteosarcoma tumor-inhibiting effects in vitro and in vivo. Overall, HPPH/EPI/CPP-pGO might be a promising therapeutic nanomedicine for osteosarcoma targeting chemotherapy. 


\section{DATA AVAILABILITY STATEMENT}

The raw data supporting the conclusions of this article will be made available by the authors, without undue reservation.

\section{ETHICS STATEMENT}

The animal study was reviewed and approved by Ethics Committee of Sichuan University.

\section{AUTHOR CONTRIBUTIONS}

YZ and YW conceived the study and the figures. TL and SS collected the data. YC wrote the manuscript and drew the figures.

\section{REFERENCES}

Cacan, E., and Ozmen, Z. C. (2020). Regulation of Fas in response to bortezomib and epirubicin in colorectal cancer cells. J. Chemother. 32, 193-201. doi:10. 1080/1120009x.2020.1740389

Cao, X. W., Yang, X. Z., Du, X., Fu, L. Y., Zhang, T. Z., Shan, H. W., et al. (2018). Structure optimisation to improve the delivery efficiency and cell selectivity of a tumour-targeting cell-penetrating peptide. J. Drug Targeting 26 (9), 777-792. doi:10.1080/1061186x.2018.1424858

Chen, L., Ye, X., Hu, K., Zhai, Y., Li, W., Wang, X., et al. (2019). Population pharmacokinetic modeling and simulation of HPPH in chinese patients with esophageal carcinoma. Xenobiotica 50 (2), 180-187. doi:10.1080/00498254. 2019.1597315

Deb, A., and Vimala, R. (2017). Camptothecin loaded graphene oxide nanoparticle functionalized with polyethylene glycol and folic acid for anticancer drug delivery. J. Drug Delivery Sci. Technol. 43, 333-342. doi:10.1016/j.jddst.2017.10.025

Dorniani, D., Saifullah, B., Barahuie, F., Arulselvan, P., Hussein, M. Z., Fakurazi, S., et al. (2016). Graphene Oxide-Gallic Acid Nanodelivery System for Cancer Therapy. Nanoscale Res. Lett. 11, 491. doi:10.1186/ s11671-016-1712-2

Dubikovskaya, E. A., Thorne, S. H., Pillow, T. H., Contag, C. H., and Wender, P. A. (2008). Overcoming multidrug resistance of small-molecule therapeutics through conjugation with releasable octaarginine transporters. Proc. Natl. Acad. Sci. U.S.A. 105, 12128-12133. doi:10.1073/pnas.0805374105

Düzgüneş, N., Piskorz, J., Skupin-Mrugalska, P., Goslinski, T., Mielcarek, J., and Konopka, K. (2018). Photodynamic therapy of cancer with liposomal photosensitizers. Ther. Delivery 9 (11), 823-832. doi:10.4155/tde-20180050

Elkordy, M. A., Elbaradie, T. S., Elsebai, H. I., Amin, E. W., and Khairalla, S. M. (2018). Osteosarcoma of the jaw: Challenges in the diagnosis and treatment. J. Egypt. Natl. Cancer Inst. 30, 7-11. doi:10.1016/j.jnci.2018. 02.001

Fink, C, Enk, A, and Gholam, P (2015). Photodynamic therapy--aspects of pain management. J. Dtsch Dermatol Ges. 13, 15-22. doi:10.1111/ddg.12546

Harrison, D. J., Geller, D. S., Gill, J. D., Lewis, V. O., and Gorlick, R. (2017). Current and future therapeutic approaches for osteosarcoma. Expert Review Anticancer Ther. 18 (1), 39-50. doi:10.1080/14737140.2018.1413939

Hwang, D.W., Kim, H.Y., Li, F., Park, J. Y., Kim, D., Park, J. H., et al. (2017). In vivo visualization of endogenous miR-21 using hyaluronic acid-coated graphene oxide for targeted cancer therapy. Biomaterials 121, 144-154. doi:10.1016/j. biomaterials.2016.12.028

Izgi, K., Iskender, B., Sakalar, C., Arslanhan, A., Yuksek, E. H., Hizar, E., et al. (2016). Effects of Epirubicin and Cisplatin Against 4T1 Breast Cancer Cells are Enhanced by Myrtucommulone-A. Anti-Cancer Agents Med. Chem. 17, 404. doi:10.2174/1871520616666160404110543
YZ and YC coordinated the study. All authors read and approved the final version of the manuscript.

\section{ACKNOWLEDGMENTS}

We are grateful to YM for help in improving this manuscript.

\section{SUPPLEMENTARY MATERIAL}

The Supplementary Material for this article can be found online at: https://www.frontiersin.org/articles/10.3389/fmolb.2020.618896/ full\#supplementary-material.

Joshi, R. K., Alwarappan, S., Yoshimura, M., Sahajwalla, V., and Nishina, Y. (2015) Graphene oxide: the new membrane material. Appl. Mater. Today 1, 1-12. doi:10.1016/j.apmt.2015.06.002

Kovbasyuk, L., and Mokhir, A. (2016). Toxicity Studies and Biomedical Applications of Graphene Oxide: . Hoboken, NJ John Wiley \& Sons, Ltd. doi:10.1002/9781119069447.ch11

Lee, J. Y., Choi, Y. S., Suh, J. S., Kwon, Y. M., Yang, V. C., Lee, S. J., et al. (2011). Cell-penetrating chitosan/doxorubicin/TAT conjugates for efficient cancer therapy. Int. J. Cancer 128, 2470. doi:10.1002/ijc.25578

Lv, Y., Tao, L., Annie Bligh, S. W., Yang, H., Pan, Q., and Zhu, L. (2016). Targeted delivery and controlled release of doxorubicin into cancer cells using a multifunctional graphene oxide. Mater Sci. Eng. C Mater Biol. Appl. 59, 652-660. doi:10.1016/j.msec.2015.10.065

Maria, C. N., Trafani, D. M. M., Pereira, F. L., Lucas, P. F., Cláudio, T. A. n., Paula, R., et al. (2018). Combining photodynamic therapy and chemotherapy: Improving breast cancer treatment with nanotechnology. J. Biomed. Nanotechnol. 14, 994-1008. doi:10.1166/ jbn.2018.2558

Ottaviani, G., and Jaffe, N. (2009). The epidemiology of osteosarcoma. Cancer Treat Res. 152, 3-13. doi:10.1007/978-1-4419-0284-9_1

Ozog, D. M., Rkein, A. M., Fabi, S. G., Gold, M. H., Goldman, M. P., Lowe, N. J., et al. (2016). Photodynamic therapy: a clinical consensus guide. Dermatol. Sur. 42 (7), 804-827. doi:10.1097/DSS.0000000000000800

Pan, X. K., Fei, S. U., Li-Hua, X. U., Yang, Z. S., Wang, D. W., Yang, L. J., et al. (2018). DJ-1 alters epirubicin-induced apoptosis via modulating epirubicinactivated autophagy in human gastric cancer cells. Curr. Med. Sci. 38, 1018-1024. doi:10.1007/s11596-018-1978-y

Plosker, GL, and Faulds, D (1993). Epirubicin. A review of its pharmacodynamic and pharmacokinetic properties, and therapeutic use in cancer chemotherapy. Drugs 45, 788-856. doi:10.2165/00003495-199345050-00011

Ramsey, J. D., and Flynn, N. H. (2015). Cell-penetrating peptides transport therapeutics into cells. Pharmacol. Ther. 154, 78. doi:10.1016/j.pharmthera. 2015.07.003

Rosli, N. F., and Fojtů, M., Fisher, A. C., and Pumera, M. (2019). Graphene oxide nanoplatelets potentiate anticancer effect of cisplatin in human lung cancer cells. Langmuir 35 (8), 3176-3182. doi:10.1021/acs.langmuir. 8 b03086

Shafirstein, G., Rigual, N. R., Arshad, H., Cooper, M. T., Bellnier, D. A., Wilding, G., et al. (2016). Photodynamic therapy with 3-(1'-hexyloxyethyl) pyropheophorbide-a for early stage cancer of the larynx: Phase Ib study. Head Neck 38, E377-E383. doi:10.1002/hed.24003

Stock, E. O., Ferrara, C. T., O’Connor, P. M., Naya-Vigne, J. M., Frost, P. H., Malloy, M. J., et al. (2018). Levels of prebeta-1 high-density lipoprotein are elevated in 3 phenotypes of dyslipidemia. J. Clin. Lipidol. 12, 99-109. doi:10.1016/j.jacl.2017.11.001

Tracy, E. C., Bowman, M. J., Pandey, R. K., and Baumann, H. (2018). Cellspecific Retention and Action of Pheophorbide-based Photosensitizers in 
human lung cancer cells. Photochem. Photobiol. 95 (3), 846-859. doi:10.1111/ php. 13043

Yu, L., Meng, M., Bao, Y., Zhang, C., and Luo, W. (2019). miR-1301/TRIAP1 Axis Participates in Epirubicin-Mediated Anti-Proliferation and Pro-Apoptosis in Osteosarcoma. Yons Med. J. 60, 832. doi:10.3349/ymj.2019.60.9.832

Wentrup, R., Winkelmann, N., Mitroshkin, A., Prager, M., Voderholzer, W., Schachschal, G., et al. (2016). Photodynamic therapy plus chemotherapy compared with photodynamic therapy alone in hilar nonresectable cholangiocarcinoma. Gut Liver 10, 470. doi:10.5009/gnl15175

Zhang, L., Zhang, Y., Tai, L., Jiang, K., Xie, C., Li, Z., et al. (2016). Functionalized cell nucleus-penetrating peptide combined with doxorubicin for synergistic treatment of glioma. Acta Biomater 42, 90. doi:10.1016/j.actbio.2016.06.031

Zhi, F., Dong, H., Jia, X., Guo, W., Lu, H., Yang, Y., et al. (2013). Functionalized graphene oxide mediated adriamycin delivery and miR-
21 gene silencing to overcome tumor multidrug resistance in vitro. PLos One 8, e60034. doi:10.1371/journal.pone.0060034

Conflict of Interest: The authors declare that the research was conducted in the absence of any commercial or financial relationships that could be construed as a potential conflict of interest.

Copyright $\odot 2021$ Zhang, Wu, Lan, Chen and Su. This is an open-access article distributed under the terms of the Creative Commons Attribution License (CC BY). The use, distribution or reproduction in other forums is permitted, provided the original author(s) and the copyright owner(s) are credited and that the original publication in this journal is cited, in accordance with accepted academic practice. No use, distribution or reproduction is permitted which does not comply with these terms. 